\title{
Lider-Üye Etkileşiminin Öğretmen Stres, Tükenmişlik ve Depresyonu Üzerindeki Rolü
}

\author{
Selçuk Demir ${ }^{1}$
}

Öz

Örgütlerde performans ve verimlilik artışına katkı sağlayan en önemli kavramlardan biri lider-üye etkileşimidir. Lider-üye etkileşimi, lider ve izleyen arasındaki çift yönlü ilişkiye odaklanmaktadır. Bu araştırmada; lider-üye (okul yöneticisi-öğretmen) etkileșimi ile öğretmenin stres, tükenmişlik ve depresyon düzeyi arasındaki ilişkinin açığa çıkarılması amaçlanmıştır. Çalışma, ilişkisel tarama modelinde tasarlanmıştır. Araştırmanın örneklemini; Hatay ilinde bulunan okullarda, 2018-2019 eğitimöğretim yılında görev yapmakta olan öğretmenler arasından, küme örnekleme yöntemiyle yansız olarak seçilmiş 48 okuldaki 437 öğretmen oluşturmaktadır. Veriler; Lider-Üye Etkileşim Ölçeği, Stres Ölçeği, Tükenmislik Ölçeği ve Depresyon Ölçeği vasıtasıyla toplanmıștır. Ölçüm modeli, değișkenlerin birbiriyle istatistiki olarak anlamlı ilişkiye sahip olduğunu göstermektedir. Yapısal eşitlik modellemesi sonuçları; lider-üye etkileşiminin, öğretmenlerin stres ve tükenmişlik düzeyleri üzerinde istatistiki açıdan anlamlı ve negatif olarak etkisi olduğunu göstermektedir. Lider-üye etkileșimi; öğretmenlerin depresyon düzeylerini, stres ve tükenmişliğin tam aracılık etkisiyle negatif olarak etkilemektedir. Elde edilen bulgulara dayalı olarak; öğretmenlerin negatif duygularını azaltmak veya oluşumunu önlemek için okul yöneticisiöğretmen etkileşiminin kaliteli olması gerekli görülmektedir.

\author{
Anahtar Sözcükler \\ Lider-üye etkileșimi \\ Stres \\ Tükenmişlik \\ Depresyon \\ Makale Hakkında \\ Gönderim Tarih \\ 13 Ocak 2019 \\ Kabul Tarihi \\ 24 Temmuz 2019 \\ Makale Türi \\ Araștırma Makalesi
}

\section{The Role of Leader-Member Exchange in Teacher Stress, Burnout, and Depression}

\section{Abstract}

Leader-member exchange is one of the most important concepts that contributes to the increase of performance and productivity in organizations. Leader-member exchange focuses on the two sided relationship between leader and follower. The aim of this study is to examine the relationship between leader-member exchange (school administrator-teacher) and teacher's level of stress, burnout and depression. This research was designed by relational model. The sample consists of 437 teachers that were randomly selected with cluster sampling method from 48 schools in Hatay city during 2018-2019 academic year. Data were gathered via Leader-Member Exchange Scale, Stress Scale, Burnout Scale and Depression Scale. The measurement model shows that research variables have statistically significant relationships with each other. Structural equation modeling points out that leader-member exchange has a statistically significant and negative impact on teachers' level of stress and burnout. Leader-member exchange negatively influences teachers' depression level through the full mediation effects of stress and burnout. Based on the findings of this current study, in order to reduce teachers' negative feelings or prevent it from occurring, a quality administrator-teacher exchange is required.
Keywords

Leader-member exchange

Stress

Burnout

Depression

Article Info

Received

January 13, 2019

Accepted

July 24, 2019

Article Type

Research Paper

Atıf: Demir, S. (2019). Lider-üye etkileşiminin öğretmen stres, tükenmişlik ve depresyonu üzerindeki rolü. Ege Eğitim Dergisi, 20(1), 291-304. doi:10.12984/egeefd.512319

\footnotetext{
1 (1) Milli Eğitim Bakanlığı, Hatay, Türkiye, selcukdemirs3@gmail.com
} 


\section{Extended Abstract}

\section{Introduction}

Leader-member exchange concentrates on the two sided relationships between leader and member. This theory asserts that leader displays different approaches to every follower (Lunenburg \& Ornstein, 2012). Previous research indicates that whereas salary, promotion, and personnel benefit are not the most important variables of raising employees' positive outputs; the quality of the relations is the most important variable (Robbins, Decenzo, \& Coulter, 2013; Tucker \& Allman, 2004). The quality of leader-member exchange influences leader's power and impression on followers (Northouse, 2013). Also stress, burnout, and depression are negative emotions that are related to each other that cause negative outputs by reducing satisfaction and the quality of work. Despite these facts, there is a lack on the topic of leader-member exchange especially in educational organizations. There are no studies that deal with a conceptual framework detecting the relationships among leader-member exchange, stress, burnout, and depression. It is seen important to examine the relationship between negative attitudes and leader-member exchange as well as positive attitudes to get more conceptual knowledge.

In this study, the role of leader-member (school administrator-teacher) exchange in teachers' negative attitudinal outcomes has been examined. Regarding to this role, a structural model has been suggested and this proposed structural model has been tested. Also in this model, the mediator effects of stress and burnout has been determined in the relationship between leader-member exchange and depression. In this study it has been aimed to point out the relationship between leader-member exchange (school administrator-teacher) and stress, burnout and depression. In line with the main purpose of this study, the following hypothesizes have been suggested:

H1: Leader-member exchange negatively affects teacher's stress.

H2: Leader-member exchange negatively affects teacher's burnout.

H3: Leader-member exchange negatively affects teacher's depression.

H4: Stress positively affects burnout.

H5: Stress positively affects depression.

H6: Burnout positively affects depression.

\section{Method}

This research was designed in relational model to reveal the coexistence and/ or level of the variables (Büyüköztürk, Çakmak, Akgün, Karadeniz, \& Demirel, 2012; Karasar, 2012). Teachers' perceptions regarding to leader-member exchange, their level of stress, burnout and depression were measured via the scales. While leader-member exchange has been analyzed as an exogenous variable; stress, burnout and depression have been analyzed as endogenous variables in AMOS program. After finding out the statistically significant correlations among variables, the path analysis was conducted in accordance with the conceptual framework. Then the insignificant paths were deleted from the structural model. Thus, the last structural model that has produced the best fit indices was achieved.

Data of this research were gathered via five-point Likert-type scales. Leader-Member Exchange Scale, Stress Scale, Burnout Scale and Depression Scale were used as data collection tools. 437 teachers working at 48 schools in Hatay city in the 2018-2019 academic year agreed to participate in this research.

Leader-member exchange scale was administered to measure the interaction between school administrator and teacher. This scale was developed as four dimensional (effect, loyalty, contribution and professional respect) by Liden and Maslyn (1998). Cronbach's Alpha Reliability Coefficient has been calculated as .92 for effect subdimension, .89 for loyalty sub-dimension, .88 for contribution sub-dimension, .93 for professional respect and .95 for overall.

Stress scale has been used for measuring teachers' stress level, was developed by Karakus (2013). The scale has a single dimension and 4 items. Cronbach's Alpha Reliability Coefficient has been calculated as .90.

Burnout scale, which has been used to determine teachers' burnout level, was developed by Pines (2005) and adapted to Turkish by Tümkaya, Çam and Çavuşoğlu (2009). The scale has one dimension and 10 items. Cronbach's Alpha Reliability Coefficient has been determined as .95. 
Depression scale, which was utilized to measure depression level of teachers, is among International Personality Pool scales (Goldberg, 1999; Goldberg et al., 2006) and adapted to Turkish by Karakuş (2013). The scale has one dimension and 6 items. Cronbach's Alpha Reliability Coefficient has been determined as .95.

\section{Findings}

The last structural equation modelling points out that leader-member exchange negatively influences teachers' stress and burnout. Leader-member exchange does not have a direct effect on teachers' depression, but it has an indirect negative effect through the full mediation effect of stress and burnout. Both stress and burnout have the role of full mediator in the relationship between leader-member exchange and depression. Stress has a positive effect on burnout and depression. Burnout positively influences depression. All the hypothesizes except one proposed in this research have been supported. Hypothesis 3 is not supported. So it seems that although leadermember exchange cannot reduce depression directly, some indirect mechanisms (stress and burnout) do exist.

\section{Discussion and Conclusion}

In this research it has been revealed that leader-member exchange has reduced teachers' stress and burnout. Similarly Nufer (2012) has found leader-member exchange is a predictor of stress and burnout. Bolat (2011) and Lee and Ji (2018) have pointed out that leader-member exchange has a negative significant impact on burnout. Findings of this current study has been supported by the previous research.

Earlier studies indicate that intensive and protracted stress causes burnout (Cordes \& Dougherty, 1993; Hock, 1988; Kyriacou, 2000; Russel, Altmaier, \& Van Velzen, 1987; Sarros \& Sarros, 1987). Teachers' intensive and protracted stress can be decreased by the help of school administrators. This can be effective in preventing negative feelings such as professional fatigue and unwillingness to work. Similarly, it has been found out in present study that leader-member interaction can decrease burnout by partial mediation effect of the stress.

When there is no quality leader-member interaction, the positive effect of the leader on the employees decreases and the negative effect increases (Atwater \& Carmeli, 2009; Graen \& Uhl-Bien, 1995; Lee \& Ji, 2018; Nufer, 2012). One of these negative aspects is depression. Besse, Howard, Gonzalez, and Howard (2015) have clarified that low-grade job satisfaction, high grade experience of stress, mental and physical sicknesses of teachers are basic predictors of the depression. It has been discerned in this research that leader-member exchange has no direct impact on depression. In addition to acquired results of this research, it has been detected that there is a negative and significant relationship between leader-member exchange and depression with the full mediation effect of the stress and burnout. In other words, leader-member exchange negatively affects depression by reducing negative attitudes that lead to depression such as stress and burnout. If the causes of depression are eliminated, individuals are likely to not experience this mourning and sadness. It has been seen in many studies that stress, burnout and depression are considerably affined with each other (Cordes \& Dougherty, 1993; Demir, 2018; Hock, 1988; Kreitner \& Kinichi, 2009; Kyriacou, 2000; Russel et al., 1987; Sarros \& Sarros, 1987; Schermerhorn, Hunt, Osborn, \& Uhl-Bien, 2011).

School administrators are advised to be competent with regard to the interpersonal relations. This is the important part of their job as they have to interact with employees. So, the quality of interaction comes into prominence in the interpersonal relations. If school administrator and teacher have quality interactions with each other, this state positively influences administrator and teacher. School administrators gain power and effect by taking the support of teachers. Teachers feel better and spend their energy for school objectives. 


\section{Giriş}

Lider-üye etkileşim (LÜE) kuramından önce liderliğe; lider veya izleyen (kişilik yaklaşımı, beceriler yaklaşımı ve stil yaklaşımı) ve süreç (durumsal liderlik kuramı, durumsallık kuramı ve yol-amaç kuramı) açısından yaklaşılmıştır (Northouse, 2013). Lider-üye etkileşim kuramıyla birlikte lider ve üye arasındaki çift yönlü ilişkilere odaklanılmıştır. Bu kuram ile liderin her bir astına yaklaşımının aynı olmadığı benimsenmiştir (Lunenburg ve Ornstein, 2012). Northouse (2013); lider-üye etkileşim kuramının, önceki liderlik kuramlarından farklı olarak, lider ile liderin izleyenleri arasındaki etkileşimde beklenen olası farklılıklara dikkat çektiğini belirtmiştir.

Örgütlerde performans ve verimlik artışında rol oynayan faktörlerin en önemlilerinden biri de lider-üye etkileşimidir (Ahmed, İsmail ve Amin, 2014; Atwater ve Carmeli, 2009; Saruhan ve Yıldız, 2014; Schermerhorn, Hunt, Osborn ve Uhl-Bien, 2011). Zira milyonlarca çalışan ve yüzbinlerce yönetici üzerinde araştırma yapan Gallup Organizasyonu, çalışanların üretimdeki verimliliği ve bağlllığ 1 konusunda en önemli değişkenin maaş, terfi, menfaat ya da işyeri çevresi olmadığını; yöneticiler ile çalışanlar arasındaki ilişkinin kalitesi olduğunu ortaya çıkarmıştır (Robbins, Decenzo ve Coulter, 2013; Tucker ve Allman, 2004). Lider-üye ilişkilerinin kaliteli olması; yöneticinin güç, etki ve fayda sağlaması açısından son derece etkilidir (Northouse, 2013). Astlarını seven, onlara değer veren, uyumlu, sevilen ve saygı duyulan, kabiliyetlerine güvenilen ve karakterine hayran olunan yöneticiler; emir-komuta zinciri olmaksızın astlarının işlerini en iyi şekilde yerine getirmelerini sağlamaktadır (Robbins, Decenzo ve Coulter, 2013). İşlerinde iyi olan üyeler ise kurumlarında daha az olumsuz duyguya maruz kalmaktadırlar. Bu durumların neticesi olarak üyeler, enerjilerini örgütsel faaliyetlere katılım noktasında daha fazla aktarabilme imkanı bulmaktadır (Ahmed ve diğ., 2014; Atwater ve Carmeli, 2009; Ilies, Nahrgang ve Morgeson, 2007).

Bazı araştırmalarda lider-üye etkileşiminin, stres ve tükenmişlik gibi istenmeyen çıktılarla negatif yönde ilişkili olduğu tespit edilmiştir (Bolat, 2011; Nufer, 2012; Lee ve Ji, 2018). Bu araştırmada ise lider-üye etkileşiminin, bazı olumsuz tutumlarla ilişkisi tek bir modelde ve eğitim örgütleri özelinde incelenmiştir. Bu çalşşmayla öğretmenlerin işlerinde geliştirdikleri, öğretim kalitesini olumsuz etkileyebileceği düşünülen istenmeyen duyguların azaltılmasında, okul yöneticisi-öğretmen etkileşiminin rolü belirlenmeye çalışılmıştır. Lider-üye etkileşim kavramına ilişkin daha geniş bir kavramsal çerçevenin sunulması ve diğer örgütler açısından olduğu gibi eğitim örgütlerinde de bu kavramın olumsuz bireysel çıktılarla mücadele edilmesinde işe koşulması önemli görülmüştür.

\section{Lider-Üye Etkileşimi}

Lider-üye etkileşim kuramı; rol kuramı ve sosyal değişim kuramı temel alınarak geliştirilen ve güncelliğini koruyan çağdaş bir liderlik yaklaşımıdır (Schermerhorn ve diğ., 2011). Rol kuramı, lider ve astları arasındaki rollere; sosyal değişim kuramı ise lider ve astları arasındaki etkileşime odaklanmaktadır (Erkutlu, 2014). İkililik üzerine yoğunlaşan Lider-Üye Etkileşim Kuramı, liderin her bir astıyla farklı şekilde ilişki kurduğunu ileri sürmektedir. Bu kurama göre liderin kurduğu ilişkiler, birbirinden bağımsız; diğer bir deyiş̧le kişiye özeldir (Northouse, 2013). Liderin her bir izleyeni ile geliştirdiği farklı türdeki ilişki, izleyenlerin iki gruba ayrılmasına yol açmaktadır. Grup-içindekilerle (iç gruptakiler) sevgi ve güvene dayalı bir ilişki oluşurken, grup dışındakilerle (dış gruptakiler) iş tanımları içerisinde bir ilişsi söz konusu olmaktadır (Lunenburg ve Ornstein, 2012; Schermerhorn ve diğ., 2011).

Lider-üye etkileşim kuramı; etki, bağl1lık, katkı ve profesyonel saygı olmak üzere dört alt boyuttan oluşmaktadır (Liden ve Maslyn, 1998). Bu boyutlar şu şekilde özetlenmektedir: Etki, bireylerin örgüt amaçlarının gerçekleştirilmesi amacıyla gönüllü olarak resmi rollerinin ötesinde fazladan çaba göstermeleridir. Etki; iş ya da mesleki değerlerden ziyade lider ile astının, karşlıklı ilişki ve etkileşimlerinden ortaya çıkan bir durumdur (Dienesch ve Liden, 1986); Bağlılık, lider ve astı arasındaki etkileşimin devamının sağlanması açısından kritik bir role sahiptir. Bu alt boyut, lider ve astının birbirlerine sadık kalması ve dış güçlere yönelik birbirlerini desteklemeleri ile ilişkilidir (Dienesch ve Liden, 1986; Uğurluoğlu, Şantaş ve Demirgil, 2013); Katkı, astların yapmış oldukları iş odaklı faaliyetleridir. Astların, örgütsel hedeflerin yerine getirilmesinde işe yönelik çıktıları ve bu çıktılarının kalitesi ile ilişkili olan katkı alt boyutu, liderleriyle etkileşimlerini etkilemektedir (Dienesch ve Liden, 1986; Liden ve Maslyn, 1998); Profesyonel saygı, lider ve astın örgüt içinde ya da dışında iş odaklı faaliyetlerine yönelik itibarlarının algılanma derecesidir (Dienesch ve Liden, 1986; Liden ve Maslyn, 1998; Uğurluoğlu ve diğ., 2013).

\section{Stres}

Eren (2015) ve Genç (2012) stresi, bireylerin; fizyolojik ve psikolojik yapılarını, tutum ve davranışlarını, iş verimlerini, üretkenliklerini ve kişilerarası ilişkilerini olumsuz yönde etkileyen gerilim durumu olarak tanımlamaktadırlar. Kyriacou (2000) ise stresi, bireyden yapması beklenen ile bireyin o görevi yerine getirme kabiliyeti arasındaki uyumsuzluğun bir ölçüsü şeklinde açıklamaktadır. Stres; birçok farklı tanımı yapılabilen bir 
kavram olmasının yanında çoğu çalışmada olduğu gibi bu çalışmada da bireyin, uzun süreli negatif duyguların etkisi altında kalması, şeklindeki tanımı kullanılmaktadır.

Kyriacou (2000); öğretmenlerin uzun süre strese maruz kalmalarının, istenmeyen sonuçlar doğurabileceğini ve öğretmen stresinin, öğretim kalitesini temel olarak iki şekilde düşürdüğünü ileri sürmektedir. Bunlardan birincisi, öğretmenlerin işlerinden elde ettikleri memnuniyet düzeylerini azaltmasıdır. İkincisi ise öğretmenlerin, öğrencileri ile etkileşimlerinin kalitesine olumsuz etkide bulunmasıdır. Öğretmenlerin memnuniyet düzeyleri azaldığında öğretmenlerin mesleklerine duydukları hevesleri de azalabilmekte; öğretime yönelik istekleri azaldığında ise öğretimle geçirdikleri zamanlarının kalitesi olumsuz etkilenebilmektedir (Hock, 1988). Uzun süreli stres yaşayan öğretmenlerin, sınıfın pozitif iklimine zarar veren ve öğrencilerinin cesaretini kıran tutum ve davranışlar sergileyebilecekleri akla gelmektedir.

\section{Tükenmişlik}

Sarros ve Sarros (1987); mücadele etmede başarısız olunan, yaşam kalitesini ve verimliliği etkileyen uzun süreli stresin tükenmişliğe yol açacağını belirtmektedirler. Tükenmişliğin ise bireye, örgüte ve yardım hizmeti alanlara ciddi kayıplar yaşatabileceğini ve bu nedenle önlenmesi gerektiğini açıklamaktadırlar. Benzer şekilde Kyriacou (2000); öğretmenlerin uzun süre stres yaşamalarının ve bu yoğun stresle başa çıkmada başarısız stratejilerinin, öğretmen tükenmişliği adı verilen olumsuz bir duruma neden olduğunu ifade etmektedir.

Maslach ve Jackson (1981) tükenmişliği; yardım hizmeti talep edilen bireylerin maruz kaldıkları duygusal tükenme, duyarsızlaşma ve kişisel başarının düşmesini içeren bir sendrom olarak tanımlamaktadır. Duygusal tükenme, tükenmişliğin en önemli boyutu olup bireylerin duygusal yönden kendilerini yıpranmış, aşırı yorulmuş, halsiz ve enerji kaybına uğramış hissetmeleri durumlarını içermektedir (Hock, 1988; Sarros ve Sarros, 1987). Çalışanlar, gerilim ve hüsran hissetmekte, geçmişte olduğu gibi işlerine yoğunlaşamamakta ve müşterileriyle ilgilenememektedirler (Cordes ve Dougherty, 1993). Duyarsızlaşma, iş yerinde olumlu hislerin ve idealizmin kaybolması ve sinirlilik halinde artış görülmesi durumudur (Maslack ve Jackson, 1981). Kişisel başarının azalması ise kişilerarası ilişkilerde geri durma, üretkenliğin azalması, başarısızlık ve işe ilişkin yetersizlik hissi durumlarını kapsamaktadır (Hock, 1988). Bu boyutta kişinin kendisini olumsuz olarak değerlendirmesi söz konusudur (Cordes ve Dougherty, 1993). Kyriacou (2000), öğretmen tükenmişliğinin; davranış olarak tükenme, fiziksel tükenme ve heyecanın tükenmesi olmak üzere temelde üç şekilde tükenmeye yol açacağını açıklamaktadır. Davranış olarak tükenme, öğretmenlerin işlerinden memnuniyetleri azaldığında ve geçmişteki gibi istekle çalışmadıklarında görülmektedir. Fiziksel olarak tükenme, öğretmenlerin aşırı yorgun ve enerjilerinin bittiğini hissettiklerinde ortaya çıkan bir durumdur. Heyecanın tükenmesi ise yapılması gerekli işlerden bile geri durma ve isteksizlik durumlarını kapsamaktadır.

Öğretmenlerin tükenmişlik yaşamaları, bireysel düzeyde zarara yol açtığı gibi çevresel düzeyde de ciddi zarar vermektedir (Dolgun, 2015; Hock, 1988). Tükenmişlik sendromu, öğretmenlerde fiziksel rahatsızlıklara neden olmakla kalmamakta, psikolojik ve davranışsal düzeyde de sıkıntılara kaynaklık etmektedir. Genel olarak bu rahatsızlıklar; depresyon, öfke, işten soğuma, işe devamsızlık, öğrencilerine karşı ilgisizlik ve kişisel başarısızlık gibi istenmeyen durumlara neden olmaktadır (Byrne, 1991; Russell, Altmair ve Van Velzen, 1987).

\section{Depresyon}

Uzun süren stres ve tükenmişliğin bireysel sonuçlarından biri de depresyondur (Besse, Howard, Gonzalez ve Howard, 2015). Bir bireyde yoğun ve uzun süre devam eden hüzün, keder ve yas haline depresyon adı verilmektedir (Şimşek ve Çelik, 2012). İnsanlara yardım etme ile ilişkili her sektörde, talep edenlerle birincil ilişkiler ve onların sorunlarına çözüm bulma gayretleri, çalışanlarda baskı unsuru olabilmektedir. Hatta çalışanlar, çözüm bekleyen kişilerin yaşam öyküleri ile özdeşleşip depresyona girebilmektedirler (Dolgun, 2015). Bir yakının vefatı, sınav notlarının düşük olması veya iş ortamındaki üst üste gelen olumsuzluklar; bireylerde duygusal çöküntüye neden olabilmektedir (Şimşek ve Çelik, 2012). Besse ve diğerleri (2015); kamuda çalışan öğretmenler arasında düşük iş doyumunun, yüksek düzeyde stres deneyiminin, zayıf ruh ve fiziksel hastalıkların depresyonun en temel yordayıcıları olduklarını bulmuşladır. Aynı araştırmacılar; depresyonun sağlığı etkileyebileceği, ardından hastalıkla geçen gün sayısını arttırabileceği ve buna ilave olarak işten ayrılma istekleri üzerinde de etkilerinin olabileceğini belirtmektedirler.

\section{Lider-Üye Etkileşimi ile Stres, Tükenmişlik ve Depresyon İlişsisi}

Önceki araş̧ırmalar (Ahmed ve diğ., 2014; Atwater ve Carmeli, 2009; Ilies ve diğ., 2007) lider ile izleyenleri arasında olumlu ilişkiler kurulduğunda, olumlu örgütsel ve bireysel çıktılar elde edileceğini göstermektedir. Yüksek kalitede lider-üye etkileşiminin doğal sonucu olarak, lider ve izleyenleri olumlu tutum ve davranışlara sahip olmaktadır. Dolayısıyla oluşan bu ılımlı hava hem liderin hem de çalışanların kendilerini iyi hissetmelerini sağlamaktadır. Altıntaş (2014); yöneticinin, mesai arkadaşlarının ya da belli beklentilerin gerçekleşmesini talep edenlerin tutumları gerginlik kaynağıysa ve örgütte geçinilmesi zor bireyler varsa stresli bir ortamın kaçınılmaz olduğunu belirtmektedir. Görüldüğü gibi bireyin yöneticisiyle ilişkileri, o birey için iş yerinde stres 
kaynaklarından biri olabilmektedir. Zira Genç (2012); yöneticinin destek olmasının, astların streslerini azaltacağını ileri sürmektedir. Araştırmacılar (Ahmed ve diğ., 2014; Atwater ve Carmeli, 2009; Ilies ve diğg., 2007); kaliteli lider-üye etkileşiminin işteki enerji ve üretkenliği etkilediğini açı̆̆a çıkarmışlardır. Nitekim araştırmacılar (Bolat, 2011; Lee ve Ji, 2018) lider-üye etkileşiminin, tükenmişliği azalttığını bulmuştur. Nufer (2012) ise lider-üye etkileşiminin hem stres hem de tükenmişlik üzerinde negatif etkisini ortaya koymuştur.

Okul yöneticisi ile kaliteli bir etkileşime sahip öğretmenler, iç grupta yer almaktadırlar. İç grupta yer alanların ayrıcalıklı olduğu; onlarla sevgi ve güvene dayalı ilişkilerin varlığı bilinmektedir (Lunenburg ve Ornstein, 2012). Olumsuz duyguları daha az hisseden öğretmenlerin, iç grupta yer aldığı tahmin edilebilir. Lunenburg ve Ornstein (2012); okul yöneticilerine, astlarıyla daha yüksek düzeyde kaliteli etkileşimler kurmalarının tavsiye edildiğini vurgulamaktadır

Genç (2012); stresin, örgüt üyelerinin moral ve doyumunu azaltan bir kavram olduğunu belirtmektedir. Kyriacou (2000) öğretmenlerle yaptığ görüşmeler neticesinde; uzun süreli stres yaşayanların, öğretim kalitesinin düştüğünü ve memnuniyetsizliklerinin arttığını bulmuştur. Bu şekilde uzun ve yoğun stres yaşayan bireyler; oldukça fazla yıpranmakta, yorulmakta ve halsiz düşmektedirler. Bu bireyler, işlerine ilgisizlik duymaya başlamakta ve onların motivasyonları düşmektedir. Önceki çalışmalar incelendiğinde, stres ile tükenmişlik (Cordes ve Dougherty, 1993; Demir, 2018; Hock, 1988; Kyriacou, 2000; Russel ve diğ., 1987; Sarros ve Sarros, 1987; Schermerhorn ve diğ., 2011); stres ile depresyon (Besse ve diğ., 2015) ve tükenmişlik ile depresyon kavramlarının (Byrne, 1991; Russell ve diğ., 1987) birbirleriyle ilişkili oldukları görülmektedir. Kreitner ve Kinichi (2009); bir takım olumsuz hislerin, zamanla diğer olumsuz hisleri de beraberinde getirdiğini belirtmektedir.

Lider ile üye arasındaki etkileşim kalitesinin, bazı bireysel ve örgütsel çıktılar üzerinde etkili olduğunun bilinmesine rağmen (Northouse, 2013) eğitim örgütlerinde, bu konuyla ilgili sınırlı sayıda çalışmaya rastlanılmıştır (Lunenburg ve Ornstein, 2012). Sınırlı sayıda çalışmanın varlığı, lider-üye etkileşim kavramının, farklı kültürden öğretmenlerle ve farklı öğretmen tutumlarıyla incelenmesini gerekli kılmıştır. Bu araştırmada; lider-üye (okul yönetici-öğretmen) etkileşiminin, öğretmenlerin istenmeyen tutumları üzerindeki rolü incelenmiştir. $\mathrm{Bu}$ role ilişkin yapısal bir model önerilmiş ve bu model test edilmiştir. $\mathrm{Bu}$ modelde, stres ve tükenmişlik değişkenlerinin aracılık etkileri incelenmiştir. Ayrıca modelde, bir dizi olumsuz tutumun diğer olumsuz tutumları da arttırabileceği (Schermerhorn ve diğ., 2011) göz önüne alınmıştır. Böylelikle kapsamlı bir çalışma yürütülmüş ve değişkenler arası ilişkilere yönelik daha sağlıklı çıkarımlar yapılmasına imkan sağlanmıştır. Bu araştırmada; okul yöneticilerinin, öğretmenlerle yüksek kalitede etkileşimler geliştirmelerinin, öğretmenlerin olumsuz tutumları üzerindeki etkisi ortaya koyulmaktadır. Araştırmanın amacı, lider-üye etkileşimi ile stres, tükenmişlik ve depresyon arasındaki ilişkiyi açığa çıkarmaktır. Araştırmada önerilen hipotezlere ilişkin model Şekil 1'de görülmektedir.

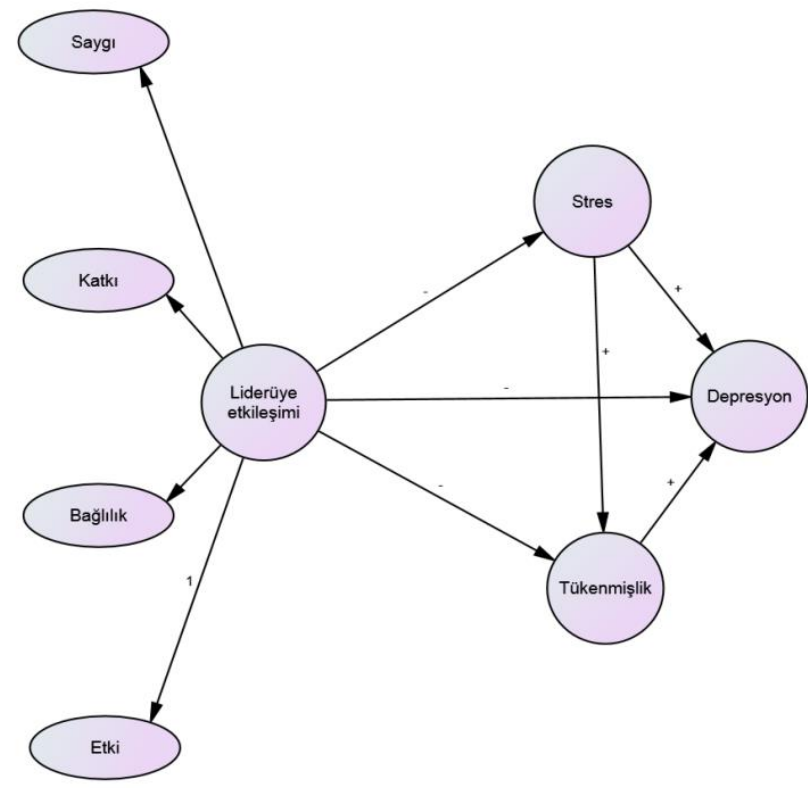

Şekil 1. Araştırma çerçevesi 
Araştırmanın temel amacı esas alınarak önerilen hipotezler aşağıda belirtilmektedir:

H1: Lider-üye etkileşimi, öğretmen stresini negatif olarak etkilemektedir.

H2: Lider-üye etkileşimi, öğretmen tükenmişliğini negatif olarak etkilemektedir.

H3: Lider-üye etkileşimi, öğretmen depresyonunu negatif olarak etkilemektedir.

H4: Stres, tükenmişliği pozitif olarak etkilemektedir.

H5: Stres, depresyonu pozitif olarak etkilemektedir.

H6: Tükenmişlik, depresyonu pozitif olarak etkilemektedir.

\title{
Yöntem
}

\begin{abstract}
Araştırmanın Deseni
$\mathrm{Bu}$ araştırmada, iki ya da daha fazla değişken arasındaki ilişkilerin yönü ve düzeyinin açığa çıkarıldığı ilişkisel tarama modeli (Büyüköztürk, Çakmak, Akgün, Karadeniz ve Demirel, 2012; Karasar, 2012) kullanılmıştır. Lider-üye (okul yönetici-öğretmen) etkileşimine, stres, tükenmişlik ve depresyon düzeylerine ilişkin öğretmen algıları yararlanılan ölçekler aracılığıyla tespit edilmiştir. Bu değişkenler arası ilişkilerin yönü ve düzeyi açığa çıkarıldıktan sonra araştırma bulgularına daha güçü kanıtlar sunulması için yol analizi yapılmıştır. Lider-üye etkileşimi ekzojen değişken; stres, tükenmişlik ve depresyon değişkenleri endojen değişkenler olarak AMOS programı aracılığıyla analize alınmıştır.
\end{abstract}

\section{Evren ve Örneklem}

Çalışma evreni, Hatay ilindeki ilkokul, ortaokul ve liselerde çalışmakta olan öğretmenlerden oluşmaktadır. Araştırma evreninin; ilkokul, ortaokul ve liseleri kapsaması, daha geniş bir hedef kitleyle çalışılmasını mümkün hale getirmiştir. Bu araştırmada; seçkisiz olarak belirlenen grupların, örneklem için seçilmesi olarak tanımlanan oransız küme örnekleme yöntemi kullanılmıştır. Çalışma evreni olan Hatay’daki her okul bir küme olarak kabul edilip 48 okul tesadüfi bir şekilde seçilmiştir. Belirlenen bu okullardaki 437 öğretmen, çalışmaya katılmıştır. Katılımcı sayısının çalışma evrenini temsil etmede \% 95 güven düzeyi için yeterli olduğu görülmüştür (Field, 2009; Özdamar, 2003).

Araştırmaya katılanların $(n=437) \%$ 48.50'si kadınlardan $(n=225)$, \% 51.50'si erkeklerden $(n=212)$ oluşmaktadır. Evli katılımcılar $(n=314)$ örneklemin \% 71.90’ını, bekar katılımcılar ise $(n=123) \% 28.10$ 'unu oluşturmaktadır. Öğretmenlerin en sık bulundukları yaş aralığ $\% 41$ ile 31-40 yaş aralığ $(n=179)$ olup en az bulundukları yaş aralığı ise \% 22.70 ile 41 yaş ve üstü yaş aralığıdır $(n=99)$.

\section{Veri Toplama Araçları}

Araştırmanın verileri; Lider-Üye Etkileşimi Ölçeği, Stres Ölçeği, Tükenmişlik Ölçeği ve Depresyon Ölçeği aracılığıyla elde edilmiştir. Kullanılan her bir ölçeğe ilişkin açımlayıcı faktör analizi bilgileri ve doğrulayıcı faktör analizleri ile güvenirlik analizleri sonucu elde edilen çıktılar aşağıda özetlenmektedir.

Lider-Üye Etkileşim Ölçeği. Lider-üye etkileşim ölçeği, dört boyutlu (etki, bağlılık, katkı ve profesyonel saygı) olarak Liden ve Maslyn (1998) tarafından geliştirilmiştir. Bu ölçek; Yıldız, Özutku ve Cevrioğlu (2008) tarafından Türkçe'ye uyarlanmış ve araştırmacılar çalışmalarında ölçeği üç boyutlu (etki, katkı ve profesyonel saygı) olarak elde etmişlerdir. Aynı araştırmacılar çalışmalarında, Lider-üye etkileşim ölçeğinin orijinal formundaki bağlılık alt boyutunun güvenirlik katsayı düşük çıktığından bu alt boyutla ilgili maddeleri ölçekten çıkarmışlardır. Bu araştırma kapsamında ise ölçeğin dört boyutlu (etki, bağlılık, katkı ve profesyonel saygı) ve 12 maddeden oluşan orijinal formu elde edilmiştir. Elde edilen bu dört boyutlu ölçeğin, Bartlett testi sonucu anlamlı ve Kaiser-Meyer-Olkin (KMO) katsayısı .94 olarak hesaplanmıştır. Açımlayıcı faktör analizi, ölçeğin orijinal formundaki gibi her boyutun üç maddeden oluştuğunu göstermiştir. Bu dört faktör, ölçme aracındaki toplam varyansın \% 85.65'ini açıklamıştır. $\mathrm{Bu}$ araştırmada yapılan güvenirlik analizi sonucunda, Cronbach's Alpha Güvenirlik Katsayısı; etki alt boyutu için .92, bağlılık alt boyutu için .89, katkı alt boyutu için .88, profesyonel saygı alt boyutu için .93 ve genel toplam için ise .95 olduğu görülmüştür. Ölçeğin yüksek düzeyde güvenilir olduğu tespit edilmiştir. Doğrulayıcı faktör analizi sonucunda, dört boyutun ve bu boyutlara ait 12 maddenin oluşturduğu faktör yapısının iyi düzeyde uyum değerlerine sahip olduğu görülmüştür.

Stres Ölçeği. Bu ölçek, Karakuş (2013) tarafından geliştirilmiştir. Bu araştırma kapsamında, ölçeğin Bartlett testi sonucu anlamlı ve Kaiser-Meyer-Olkin (KMO) katsayısının .77 olduğu görülmüştür. Stres ölçeği tek boyut ve 4 maddeden oluşmaktadır. Ölçekteki tek faktör, toplam varyansın \% 77.21'ini açıklamaktadır. Faktör yükleri .85 ile .91 arasında farklılık göstermektedir. Bu araştırmada yapılan güvenirlik analizi sonucunda, Cronbach's Alpha Güvenirlik Katsayısı .90 olarak bulunmuştur. Dolayısıyla ölçeğin, yüksek düzeyde güvenilir olduğu 
belirlenmiştir. Doğrulayıcı faktör analizi, stres ölçeğinin faktör yapısının uyum değerlerinin kabul edilebilir düzeyde olduğunu göstermiştir.

Tükenmişlik Ölçeği. Pines (2005) tarafindan geliştirilen ve Tümkaya, Çam ve Çavuşoğlu (2009) tarafindan Türkçeye uyarlanan tükenmişlik ölçeğinin 10 maddeden oluşan kısa versiyonu kullanılmıştır. Bu araştırma kapsamında, ölçeğin; Bartlett Küresellik Testi anlamlı ve Kaiser-Meyer-Olkin (KMO) katsayıs1 .938 olarak hesaplanmıştır. Ölçek maddelerinin faktör yüklerinin .43 ile .74 arasında değiştiği görülmektedir. Tükenmişlik ölçeğindeki tek faktör, ölçme aracındaki toplam varyansın \% 70.64'ünü açıkladığı tespit edilmiştir. Bu araştırmanın veri setine uygulanan güvenirlik analizi sonucunda, ölçeğin Cronbach's Alpha Güvenirlik Katsayısı .95 olarak hesaplanmıştır. Ölçek, yüksek düzeyde güvenilirdir. Doğrulayıcı faktör analizi, ölçeğin faktör yapısının iyi düzeyde uyum değerleri ürettiğini göstermektedir.

Depresyon Ölçeği. Depresyonu ölçmek için, International Personality Item Pool ölçekleri arasında bulunan (Goldberg, 1999; Goldberg ve diğ., 2006) ve Karakuş (2013) tarafindan Türkçeye uyarlanan depresyon ölçeği kullanılmıştır. Ölçek tek faktörlü olup 5 maddeden oluşmaktadır. Bu araştırma kapsamında, ölçeğin; Bartlett Küresellik Testi anlamlı ve Kaiser-Meyer-Olkin (KMO) katsayısı .88 olarak hesaplanmıştır. Ölçek maddelerinin faktör yükleri .87 ile .94 arasında değiştiği görülmektedir. Depresyon ölçeğindeki tek faktörün, ölçme aracındaki toplam varyansın \% 84.73'ünü açıkladığı tespit edilmiştir. Bu araştırmada yapılan güvenirlik analizi sonucunda, ölçeğin Cronbach's Alpha Güvenirlik Katsayısı .95 olarak hesaplanmıştır. Ölçek, yüksek düzeyde güvenilirdir. Doğrulayıcı faktör analizi sonucunda ölçeğin tek boyutlu faktör yapısının iyi düzeyde uyum değerleri ürettiği tespit edilmiştir.

Bu araştırmada her bir ölçek için doğrulayıcı faktör analizi uygulanmış olup bazı kriterler için uyum değerleri aşağıdaki Tablo 1'de görülmektedir.

Tablo 1

DFA Sonucu Ölçeklerin Uyum İyiliği Değerleri

\begin{tabular}{llllllllll}
\hline Ölçekler & $x^{2}$ & $s d$ & $x^{2} / s d$ & $p$ & $G F I$ & $I F I$ & $T L I$ & CFI & RMSEA \\
\hline LÜE & 176.21 & 47 & 3.74 & .00 & .94 & .97 & .96 & .97 & .07 \\
Stres & 3.87 & 1 & 3.87 & .00 & .99 & .99 & .97 & .99 & .07 \\
Tükenmişlik & 12.58 & 9 & 1.39 & .18 & .99 & .99 & .99 & .99 & .03 \\
Depresyon & .11 & 1 & .11 & .73 & 1.00 & 1.00 & 1.00 & 1.00 & .00 \\
\hline
\end{tabular}

Tablo 1 incelendiğinde $x^{2} / s d$ oranın, lider-üye etkileşimi ve stres değişkenleri için 2 ile 5 arasında olduğu dolayısıyla kabul edilebilir bir uyumun varlığı; tükenmişlik ve depresyon değişkenleri için ise bu oranın 2'nin altında olduğu dolayısıyla iyi bir uyumun varlığı görülmektedir. Lider-üye etkileşimi ve stres değişkenleri için RMSEA değeri 0.08 ile 0.05 arasında olduğu dolayısıyla kabul edilebilir; tükenmişlik ve depresyon değişkenleri için 0.05 'in altında bulunduğu dolayısıyla iyi bir uyumun varlığı anlaşılmaktadır (Çelik ve Yılmaz, 2016). Bu araştırmanın değişkenleri için GFI değerinin .90'dan büyük olduğu dolayısıyla iyi uyumun olduğu görülmektedir (Meydan ve Şeşen, 2015). Araştırma değişkenleri için IFI, CFI ve IFI değerlerinin 0.95 'ten büyük olması ise iyi bir uyumun bulunduğunu ifade etmektedir (Byrne, 2010; Kline, 2011).

\section{Veri Toplama Süreci}

2018-2019 eğitim-öğretim yılında araştırmacı tarafından, ölçeklerin bulunduğu form, tesadüfi olarak seçilen okullardaki öğretmenlere dağıtılmıştır. Öğretmenlere, araştırmaya katılımlarının tamamen gönüllülük ilkesine dayandığı belirtilmiştir. Katılımcılar; çalışmaya ilişkin amaç, konu, araştırma değişkenleri ve bilgilerin gizliliği noktalarında aydınlatılmıştır. Formlar dağıtıldıktan birkaç gün sonra doldurulan bu formlar, tekrar araştırmacı tarafından okullardan alınmıştır.

\section{Veri Analizi}

Veriler SPSS programına girilmesinin ardından uç değerler temizliği, çarpıklık ve basıklık katsayılarının kontrolü yapılmıştır. Verilerin normal dağılım gösterdiği tespit edilmiştir. Elde edilen tolerans ve VIF değerleri, bağımlı ve bağımsız değişkenler arasında çoklu bağlantı problemi olmadığını göstermiştir. "Gizil değişkenlere yol analizi yapmak için test edilen modeldeki değişkenlerin ölçümüne yönelik kullanılan tüm ölçeklerin, geçerli ve güvenilir olması gerekmektedir.” (Şimşek, 2007, s. 19). Veriler, geçerlik ve güvenirlik açısından incelenmiş; faktör analizi sonuçları ve Cronbach's Alpha güvenirlik katsayıları araştırmada kullanılan ölçeklerin geçerli ve güvenilir olduğunu ortaya koymuştur. YEM modelinin analizi için AMOS yazılımı kullanılmıştır. AMOS yazılımı güçlü çözüm alternatifi sunmaktadır (Meydan ve Şeşen, 2015).

Doğrulayıcı faktör analizi aşamasında her bir ölçeğin faktör yapıları incelenmiştir. Sonra bu aşamada üretilen uyum değerleri, bazı kriterler açısından kontrol edilmiştir. Bu kriterler şu şekilde belirtilebilir: $x^{2} / s d$ oranı 2 'nin altında olduğunda iyi bir uyumun, 2 ile 5 arasında olduğunda ise kabul edilebilir bir uyumun varlığ $;$ RMSEA 
değeri .08 ile .05 arasında bulunduğunda kabul edilebilir, .05'in altında bulunduğunda ise iyi bir uyumun varlığ ifade edilmektedir (Çelik ve Yılmaz, 2016). GFI değerinin .85 ile .90 aralığında olması kabul edilebilir uyumun ve .90 'dan büyük olması ise iyi uyumun olduğunu belirtmektedir (Meydan ve Şeşen, 2015). IFI, CFI ve IFI değerlerinin .90 ile .95 arasında olması kabul edilebilir bir uyumun, bu değerlerin .95 'ten büyük olması ise iyi bir uyumun bulunduğunu göstermektedir (Byrne, 2010; Kline, 2011).

\section{Bulgular}

Araştırma değişkenlerine ait aritmetik ortalama, standart sapma ve standart hata ile korelasyon değerleri Tablo 2 'de verilmektedir.

Tablo 2

Değişkenlere İlişkin Betimsel İstatistikler ve Korelasyon Değerleri

\begin{tabular}{|c|c|c|c|c|c|c|c|}
\hline Değişkenler & $\bar{X}$ & $s s$ & Std. Hata & 1 & 2 & 3 & 4 \\
\hline 1. Lider-Üye & 3.82 & .76 & .03 & 1 & & & \\
\hline 2. Stres & 2.60 & 1.02 & .04 & $-.19 * *$ & 1 & & \\
\hline 3. Tükenmişlik & 2.15 & .94 & .04 & $-.24 * *$ & $.68 * *$ & 1 & \\
\hline 4. Depresyon & 2.06 & 1.02 & .04 & $-.15 * *$ & $.65 * *$ & $.69 * *$ & 1 \\
\hline
\end{tabular}

Tablo 2'ye göre; öğretmenlerin lider-üye etkileşim algıları kısmen yüksek düzeydedir (4: Katılıyorum). Stres, tükenmişlik ve depresyon düzeylerine ilişkin algıları ise kısmen düşük düzeydedir (2: Katılmıyorum). Korelasyon matrisindeki ilişkiler incelendiğinde; lider-üye etkileşimi ile stres $(r=-.19, p<.01)$, tükenmişlik $(r=$ $-.24, p<.01)$ ve depresyon $(r=-.154, p<.01)$ arasında düşük düzeyde, negatif ve anlamlı bir ilişki bulunmaktadır. Stres; tükenmişlik $(r=.68, p<.01)$ ve depresyonla $(r=.69, p<.01)$ yüksek düzeyde pozitif ve anlamlı ilişkilidir. Tükenmişlik ve depresyon arasında da yüksek düzeyde, pozitif ve anlamlı ilişki bulunmaktadır $(r=.65, p<.01)$. Araştırmaya konu olan tüm değişkenlerin birbiriyle anlamlı ilişkilere sahip olduğu görülmektedir. Dolayısıyla bu sonuç, ölçüm modelinde de değişkenlerin anlamlı ilişkilere sahip olabileceğini öngörmektedir.

Ölçüm modelindeki gizil (örtük) değişkenlerin birbirleriyle anlamlı ilişkileri Şekil 2’de görülmektedir.

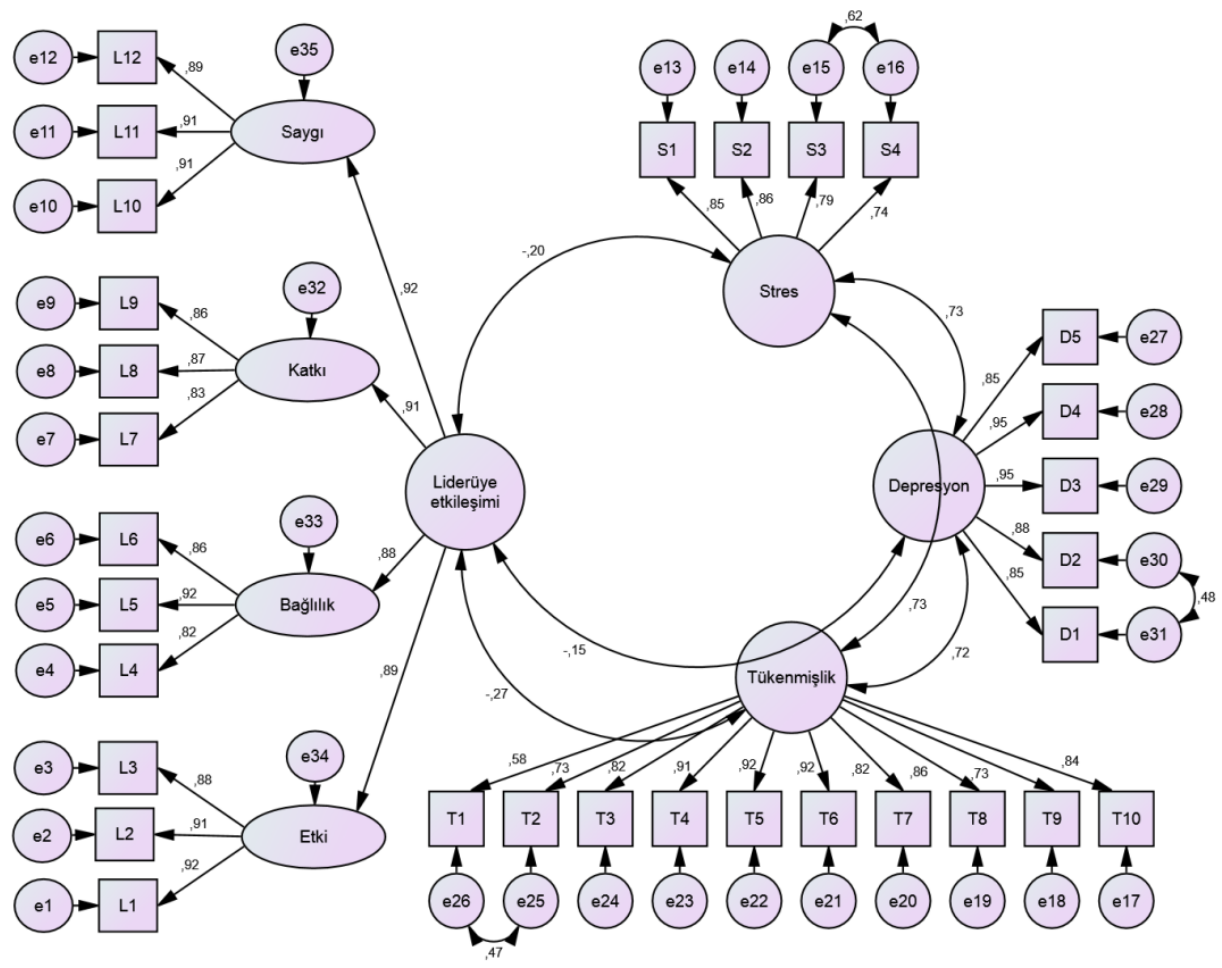

Şekil 2. Standardize Edilmiş Katsayılarla Ölçüm Modeli 
Araştırmada kullanılan ölçeklere doğrulayıcı faktör analizi uygulanmıştır. Modelden hiçbir madde çıkarılmamıştır. Ölçüm modelinde; T1 ile T2, D1 ile D2 ve S3 ile S4 maddeleri arasına bu maddelerdeki hataların birbiriyle ilişkili olmasından dolayı hata kovaryansları eklenmiştir. Araştırma değişkenlerinin birbiriyle ilişkisinin anlamlı olduğu görülmüştür. Ölçüm modeli; yararlanılan ölçeklerin, araştırma verileriyle iyi düzeyde uyumlu olduğunu göstermiştir $\left(x^{2}=1144.38, s d=421, x^{2} / s d=2.71, p=.00, G F I=.85, I F I=.94, T L I=.94, C F I\right.$ $=.94, R M S E A=.06)$. Üretilen bu uyum değerleri, yol analizinde de değişkenler arası etkilerin varlığını işaret etmektedir.

Ölçme modeli iyi uyum değerleri ürettikten sonra, örtük (gizil) değişkenler arasındaki kovaryanslar silinmiş ve önerilen hipotezler doğrultusunda örtük değişkenlere tek yönlü yollar eklenmiştir. Yol katsayısının anlamsız olmasından dolayı Lider-Üye Etkileşimi $\rightarrow$ Depresyon $(B=.057, \beta=.041, p=.256)$ yolu modelden çıkarılmıştır (Tablo 2). Bu işlemin ardından elde edilen yapısal eşitlik modelinin, araştırma verileriyle iyi uyum gösterdiği görülmüştür $\left(x^{2}=639.33, s d=339, x^{2} / s d=1.88, G F I=.86, I F I=.92, T L I=.91, C F I=.92\right.$, RMSEA $\left.=.05\right)$.

Anlamsız yolların yapısal modelden çıkarılmasına dair uyum değerleri Tablo 3 'de verilmektedir.

Tablo 3

Yapısal Modelde Anlamsiz Yollarin Silinmesi

\begin{tabular}{llllllllll}
\hline & $x^{2}$ & $s d$ & $x^{2} / s d$ & $\Delta x 2$ & GFI & IFI & TLI & CFI & RMSEA \\
\hline Doymuş model & 1144.38 & 421 & 2.71 & - & .85 & .94 & .94 & .94 & .06 \\
LÜE $\rightarrow$ Depresyon & 1145.66 & 422 & 2.71 & .00 & .85 & .94 & .94 & .94 & .06 \\
\hline
\end{tabular}

Bu araştırmada anlamsız yollar çıkarıldıktan sonra standardize edilmiş yol katsayıları ile en iyi uyum değerlerine sahip son yapısal eşitlik modeli Şekil 3’te görülmektedir.

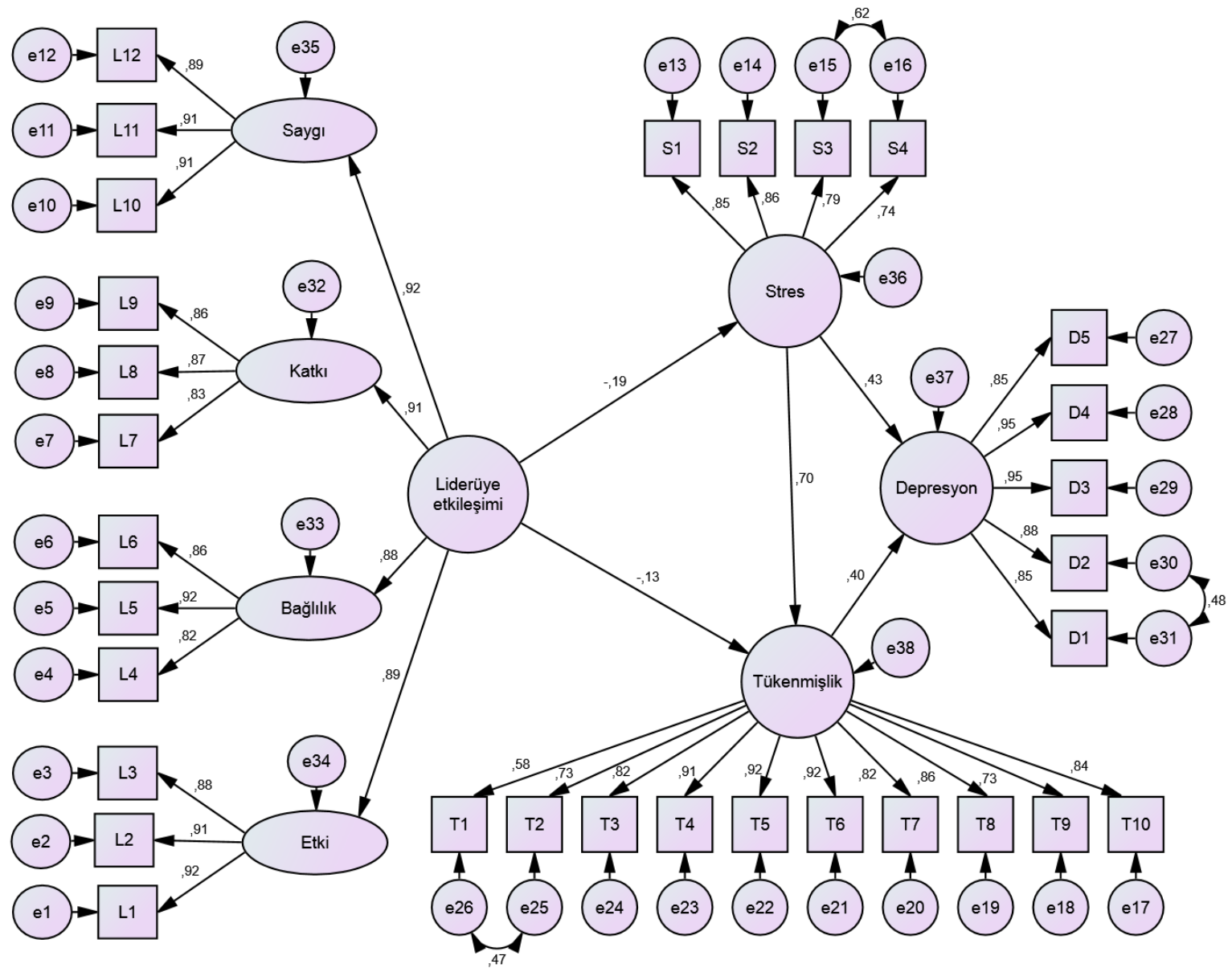

Şekil 3. Standardize edilmiş yol katsayıları ile son yapısal eşitlik modeli

En iyi uyum değerlerine sahip $\left(x^{2}=1145.66, s d=422, x^{2} / s d=2.71, p=.00, G F I=.85, I F I=.94, T L I=.94\right.$, $C F I=.94, R M S E A=.06)$ son yapısal modele göre; lider-üye etkileşimi, öğretmenlerin stres $(\beta=-.19, p<.01)$ ve 
tükenmişlik ( $\beta=-.13, p<.01)$ düzeylerini negatif olarak etkilemektedir. Lider-üye etkileşimi, stres ve tükenmişliğin tam aracılık etkisiyle depresyon üzerinde istatistiki olarak anlamlı ve negatif etkiye sahiptir $(\beta=-$ $.05, p<.01)$. Lider-üye etkileşimi, stresin $(\beta=-.08, p<.01)$ ya da tükenmişliğin $(\beta=-.05, p<.01)$ tam aracılık etkisiyle de depresyonu negatif olarak etkilemektedir.

Önceden belirtilen hipotezler doğrultusunda, H3 hipotezi hariç diğerlerinin doğrulandığ1 görülmektedir. Bu araştırmada, değişkenlerin birbirleri üzerindeki doğrudan etkilerinin yanı sıra dolaylı etkileri de açığa çıkarılmıştır. Diğer bir deyişle, değişkenlerin birbirleri üzerindeki etkisinde aracılık rolüne sahip değişkenler de tespit edilmiştir.

\section{Sonuç ve Tartışma}

$\mathrm{Bu}$ araştırmada; lider-üye etkileşiminin, öğretmenlerin olumsuz tutumlarından stres ve tükenmişlik düzeylerini azalttığı tespit edilmiştir. Kaliteli bir lider-üye etkileşimi, öğretmenlerin stres ve tükenmişliklerini azaltmaktadır. Nufer (2012); lider-üye etkileşiminin, stres ve tükenmişliğin yordayıcıları olduğunu bulmuştur. Bolat (2011) ve Lee ve Ji (2018) ise lider-üye etkileşiminin, tükenmişlik üzerinde negatif ve anlamlı etkisinin olduğunu açığa çıkarmışlardır. Şimdiki araştırma bulgusunun, diğer çalışmalarla da desteklendiği görülmektedir.

Kyriacou (2000), öğretmenlerle yaptığı görüşmelerde; öğretmenlik mesleğinin gerektirdiği bir iş yükü olduğunu ve bu iş yükünün onlarda çaresizlik hissini öne çıkardığını görmüştür. Okul yöneticisi ile öğretmen arasındaki etkileşimin kaliteli olması, öğretmene sunulan yönetici desteğinin artmasını sağlamaktadır. Uzun ve yoğun yaşanılan stresin, tükenmişliğe yol açtığı önceki çalışmalardan da bilinmektedir (Cordes ve Dougherty, 1993; Hock, 1988; Kyriacou, 2000; Russel ve diğ., 1987; Sarros ve Sarros, 1987). Okul yöneticisinin öğretmenlere eğitim-öğretim faaliyetlerinde yardımcı olması, öğretmenlerin uzun süreli ve yoğun stres yaşamalarını azaltabilir. Böylelikle öğretmenlerin, çaresizlik gibi olumsuz tutumlara sahip olmaları önlenebilir. Ayrıca bu durum, mesleki yorgunluk ve işe isteksizlik gibi olumsuz duyguların önlenmesinde etkili olabilir. Yaşanılan olumsuz duygulardan birinin azaltılması, diğer olumsuz duyguların da azalmasına yardımcı olabilir. Şimdiki araştırmada benzer olarak; lider-üye etkileşiminin, stresin kısmi aracılık etkisiyle tükenmişliği azalttığı ortaya koyulmuştur.

Etkili liderlik, kaliteli bir lider-üye etkileşimini gerektirmektedir. Kaliteli bir lider-üye etkileşimi olmadığında, liderin çalışanlar üzerindeki olumlu etkisi azalmakta ve olumsuz etkisi artmaktadır (Atwater ve Carmeli, 2009; Graen ve Uhl-Bien, 1995; Lee ve Ji, 2018; Nufer, 2012). Oluşacak bu olumsuz tutumlardan bir tanesi de depresyondur. Besse ve diğerleri (2015), kamuda görev yapan öğretmenlerle gerçekleştirdikleri çalışmada; öğretmenlerin iş doyumlarının düşük olmasının, yüksek düzeyde stres deneyimi yaşamalarının, ruhsal ve fiziksel hastalıklarının depresyonun en temel yordayıcıları olduklarını açığa çıkarmışlardır. Bu araştırmada; lider-üye etkileşiminin, depresyon üzerinde doğrudan bir etkisinin olmadığı görülmüştür. Elde edilen bu araştırma sonucunun yanı sıra lider-üye etkileşiminin, stres ve tükenmişliğin tam aracılık etkisiyle depresyon üzerinde anlamlı ve negatif bir etkisinin bulunduğu tespit edilmiştir. Diğer bir deyişle lider-üye etkileşimi, stres ve tükenmişlik gibi depresyona kaynaklık eden olumsuz tutumları azaltmak suretiyle depresyonu olumsuz etkilemektedir. Depresyonu oluşturan sebepler ortadan kaldırıldı̆̆ında, bireylerin yas ve hüzün halini de yaşamadıkları belirtilebilir. Birçok çalışmada (Cordes ve Dougherty, 1993; Demir, 2018; Hock, 1988; Kreitner ve Kinichi, 2009; Kyriacou, 2000; Russel ve diğ., 1987; Sarros ve Sarros, 1987; Schermerhorn ve diğ., 2011) stres, tükenmişlik ve depresyonun birbiriyle yakın ilişkili olduğu görülmektedir.

Yukl, O’Donnell ve Taber (2009) yöneticinin; astları sorun yaşadığında, aşırı kaygılandığında ya da kendilerini psikolojik olarak kötü hissettiklerinde, onlara destek olmalarının önemli olduğunu vurgulamaktadırlar. Ayrıca yöneticilerin, çalışanların zor ve stresli bir görev üstlendiklerinde gerginliklerini azaltabilmelerinin gerektiğini belirtmektedirler. Murray (2016) ise örgütteki bireylerin; korku, endişe, stres ve düş kırıklığ1 gibi duyguları önlenemediğinde ya da azaltılamadığında, bu kişilerde diğer bazı olumsuz tutumların da oluşacağını tespit etmiştir. Bu bağlamda yönetim kademesindeki kişilere büyük sorumluluklar düştüğü belirtilmektedir. Aynı araştırmacı bu tür olumsuz duygular yaşayan bireylerin, olumlu tutumlarının da kaybolduğunu ileri sürmektedir. $\mathrm{Bu}$ araştırma bulgularından hareketle okul yöneticilerinin; öğretmenlerin olumsuz deneyimlerden ötürü yoğun düzeyde stres ve tükenmişlik yaşamamalarında, öğretmenlerle aralarındaki etkileşim kalitesinin rolü önemli görülmektedir.

Bu çalışmayla iletişim, performans, verimlilik, üretim ve insan kaynakları yönetimi gibi birçok önemli konuya katkı yapılmaktadır. Önceki araştırma bulgularından da alınan destekle lider-üye etkileşiminin, çalışanların olumsuz tutumları üzerindeki etkisine yönelik geniş bir teorik çerçeve oluşturulmaktadır. Stres ve tükenmişlik değişkenlerinin aracılık etkilerinin test edilmesi alana sunulan bir diğer önemli katkıdır. Başka bir anlatımla lider-üye etkileşimi, öğretmenlerin; stres ve tükenmişlik düzeylerini azaltarak, depresyonu körükleyen duygularının önüne geçilebilmesine katkı sunmaktadır. Buradan hareketle öğretmenlerin bir takım olumsuz 
tutumlarının azaltılması yoluyla hem bireysel hem de çevresel olumsuz çıktıların oluşumunun önlenebilmesi mümkün olabilir.

Okul yöneticisinin mevzuat ve yönetmelik konularında bilgiye sahip olması, okulun sürdürülebilir yapıs1 açısından önemli görülmektedir (Gedikoğlu, 2015). Bunun yanı sıra okul yöneticisinin, kişilerarası ilişkiler konusunda da yetkin olması, işinin diğer bir önemli boyutunu oluşturmaktadır. Nitekim yöneticisiyle ilişkileri iyi düzeyde olan öğretmenlerin, kendilerini daha iyi hissettikleri ve enerjilerini okulun hedeflerinin gerçekleşmesi yönünde harcadıkları bilinmektedir (Lunenburg ve Ornstein, 2012). Bu araştırma sonuçlarından yüksek kalitede okul yöneticisi-öğretmen etkileşiminin, öğretmenlerin işlerinde karşılaş̧ıkları olumsuz duygularla mücadele etmelerinde önemli bir rolünün olduğu görülmektedir. Öğretmenlerin psikolojik olarak olumsuz duygulara maruz kalmamalarının, öğretim kalitesi üzerinde olumlu etkisinin olacağı düşünülmektedir. Öğretmenlerle etkileşimi kaliteli olan yöneticiler; okulun havasının olumlu olmasını, sosyal ve akademik alanlarda başarısının artmasını sağlayabilir. Bu gibi sebeplerden dolayı okul yöneticileri ile öğretmenler arasında yüksek düzeyde kaliteli etkileşimler kurulmasında fayda görülmektedir. 


\section{Kaynakça/References}

Altıntaş, E. (2014). Stres yönetimi. Ankara: Anı.

Ahmed, I., Ismail, W. K. W., \& Amin, S. M. (2014). Guanxi network and leader-member exchange: The impetus for employee creative involvement. Asia-Pacific Journal of Business Administration, 6(1), 64-77. doi:10.1108/APJBA-05-2013-0048

Atwater, L., \& Carmeli, A. (2009). Leader-member exchange, feelings of energy and involvement in creative work. Leadership Quaterly, 20(3), 264-275. doi:10.1016/j.leaqua.2007.07.009

Besse, R., Howard, K., Gonzalez, S., \& Howard, J. (2015). Major depressive disorder and public school teachers: Evaluating occupational and health predictors and outcomes. Journal of Biobehavioral Research, 20(2), 71-83. doi:10.1111/jabr.12043

Bolat, O. İ. (2011). Öz yeterlik ve tükenmişlik ilişkisi: Lider-üye etkileşiminin aracılık etkisi. Ege Akademik Bakıs, 11(2), 255-266.

Büyüköztürk, Ş., Çakmak, E. K., Akgün, Ö. E., Karadeniz, Ş. V. ve Demirel, F. (2012). Bilimsel araştırma yöntemleri. Ankara: Pegem Akademi.

Byrne, B. M. (2010). Structural equation modeling with AMOS. New York: Routledge.

Byrne, B. M. (1991). Burnout: Investigation the impact of background variables for elementary, intermediate, secondary and university educators. Teachers and Teaching Education, 7(2), 197-209. doi:10.1016/0742051X(91)90027-M

Cordes, C. L. \& Dougherty, T. W. (1993). A review and integration of research on job burnout. Academy of Management Review, 18(4), 621-656. doi:10.2307/258593

Çelik, H. E. ve Yılmaz, V. (2016). Lisrel 9.1. ile yapısal eşitlik modellemesi, Temel kavramlar- UygulamalarProgramlama. Ankara: An1.

Demir, S. (2018). The relationship between psychological capital and stress, anxiety, burnout, job satisfaction and job involvement. Eurasian Journal of Educational Research, 75, 137-154. doi:10.14689/ejer.2018.75.8

Dienesch, R. M., \& Liden, R. C. (1986), Leader-Member Exchange model of leadership: A critique and further development. Academy of Management Review, 11(3), 618-637. doi:10.5465/amr.1986.4306242

Dolgun, U. (2015). Tükenmişlik sendromu. D. E. Özler (Ed.), Örgütsel davranışta güncel konular (s. 287-310). Bursa: Ekin Basım Yayın Dağıtım.

Eren, E. (2015). Örgütsel davranış ve yönetim psikolojisi. İstanbul: Beta.

Erkutlu, H. V. (2014). Liderlik, kuramlar ve yeni bakış açıları. Ankara: Efil.

Field, A. (2009). Discovering Statistics using SPSS. Dubai: Oriental Press.

Gedikoğlu, T. (2015). Liderlik ve okul yönetimi. Ankara: An1.

Genç, N. (2012). Yönetim ve organizasyon: Çă̆daş sistemler ve yaklaşımlar. Ankara: Seçkin.

Goldberg, L. R. (1999). A broad-bandwidth, public domain, personality inventory measuring the lower-level facets of several five-factor models. In I. Mervielde, I. Deary, F. De Fruyt, and F. Ostendorf (Eds.), Personality psychology in Europe (Vol 7, pp. 7-28). Tilburg: Tilburg University Press.

Goldberg, L. R., Johnson, J. A., Eber, H. W., Hogan, R., Ashton, M. C., Cloninger, C. R., \& Gough, H. C. (2006). The international personality item pool and the future of public-domain personality measures. Journal of Research in Personality, 40, 84-96. doi:10.1016/j.jrp.2005.08.007

Graen, G. \& Uhl-Bien, M. (1995). Relationship-based approach to leadership: development of leader-member exchange theory of leadership over 25 years: applying a multi-level multi domain perspective. Leadership Quarterly, 6, 219-247.

Hock, R. R. (1988). Professional burnout among public teachers. Public Personel Management, 17(2), 167-189. doi: 10.1177/009102608801700207

Ilies, R., Nahrgang, J. D., \& Morgeson, F. P. (2007). Leader-member exchange and citizenship behaviors: A meta analysis. Journal of Applied Psychology, 92(1), 269-277. doi:10.1037/0021-9010.92.1.269.

Karakuş, M. (2013). Emotional intelligence and negative feelings: A Gender specific moderated mediation model. Educational Studies, 39(1), 68-82. doi:10.1080/03055698.2012.671514

Karasar, N. (2012). Bilimsel araştırma yöntemi. Ankara: Nobel. 
Kline, R. B. (2011). Principles and practice of structural equation modeling. New York: The Guilford Press.

Kreitner, R. \& Kinichi, A. (2009). Organizational behaviour (9th ed.). New York: Mc Graw-Hill International Edition.

Kyriacou, C. (2000). Stress busting for teachers. Cheltenham: Nelson Thornes.

Lee, E. K., \& Ji, E. J. (2018). The moderating role of leader-member exchange in the relationships between emotional labor and burnout in clinical nurses. Asian Nursing Research 12, 56-61. doi:10.1016/j.anr.2018.02.002

Liden R. C. \& Maslyn J. M. (1998). Multidimensionality of leader-member exchange: An empirical assessment through scale development. Journal of Management, 24(1), 43-72.

Lunenburg, F. C. \& Ornstein, A. C. (2012). Educational administration: Concepts and practices (Sixth Edition). Belmont, C.A.: Wadsworth Cengage Learning Publishing.

Maslach, C., \& Jackson, S. E. (1981). The measurement of experienced burnout. Journal of Occupational Behaviour, 12, 99-113. doi:10.1002/job.4030020205

Meydan, C. H. ve Şeşen, H. (2015). Yapisal eşitlik modellemesi, Amos uygulamaları. Ankara: Detay.

Murray, K. (2016). Liderlik ve iletişim. (Çev. Şensoy, Ü.). İstanbul: Türkiye İş Bankası Kültür Yayınları. (Özgün Çalışma, 2014)

Northouse, P. G. (2013). Leadership (Theory and practice). Thousand Oaks: Sage.

Nufer, S. (2012). The effects of locus of control and leader-member exchange predictors of stress and burnout in the workplace. (Unpublished doctoral dissertation). Faculty of The Chicago School of Professional Psychology, USA.

Pines, A. M. (2005). The burnout measure short version (BMS). International Journal of Stress Management, 12(1), 78-88. doi:10.1037/1072-5245.12.1.78

Özdamar, K. (2003). Modern bilimsel araştırma yöntemleri. Eskişehir: Kaan Kitabevi.

Robbins, S. P., Decenzo, D. ve Coulter, M. (2013). Yönetimin esaslarl (Çev. Ed. Öğüt, A.). Ankara: Nobel. (Özgün Çalışma, 2011)

Russell, D. W., Altmaier, E., \& Van Velzen, D. (1987). Job-related stress, social support, and burnout among classroom teachers. Journal of Applied Psychology, 72(2), 269-274. doi:10.1037//0021-9010.72.2.269

Sarros, J. C. \& Sarros, A. M. (1987). Predictors of teacher burnout. The Journal of Educational Administration, 25(2), 216-229. doi:10.1108/eb009933

Saruhan, Ş. C. ve Yıldız, M. L. (2014). Insan kaynakları yönetimi: Teori ve uygulama. İstanbul: Beta.

Schermerhorn, J. R., Hunt, J. G., Osborn, R. N., \& Uhl-Bien, M. (2011). Organizational behavior. Asia: John Wiley \& Sons (Asia) Pte Ltd.

Şimşek, Ö. F. (2007). Yapısal eşitlik modellemesine giriş, Temel ilkeler ve Lisrel uygulamaları. Ankara: Ekinoks.

Şimsek, M. ve Çelik, A. (2012). Yönetim ve organizasyon. Konya: Eğitim.

Uğurluoğlu, Ö., Şantaş, F. ve Demirgil, B. (2013). Lider-üye etkileşimi ve tükenmişlik ilişkisi: Hastanelerde bir uygulama. Haccettepe Sağllk İdaresi Dergisi, 16(1), 1-21.

Tucker, K. A., \& Allman, V. (2004). Don't be a cat and a mouse manager. The Gallup Organization, www.brain.gallup.com (September 16, 2016).

Tümkaya, S., Çam, S. ve Çavuşoğlu, I. (2009). Tükenmişlik ölçeği kısa versiyonunun Türkçeye uyarlama, geçerlik ve güvenirlik çalısması. Ç.Ü. Sosyal Bilimler Enstitüsü Dergisi, 18 (1), 387-398.

Yıldız, G., Özutku, C. ve Cevrioğlu, E. (2008). Lider-üye etkileşimine çok boyutlu yaklaşım: Liden ve Maslyn'in dört boyutlu lider-üye etkileşim ölçeğinin psikometrik özelliklerine yönelik görgül bir araştırma. Akademik Incelemeler, 3(1), 95-123.

Yukl, G., O'Donnell, M., \& Taber, T. (2009). Influence of leader behaviors on the leader-member exchange relationship. Journal of Managerial Psychology, 24(4), 289-299. doi:10.1108/02683940910952697 